\title{
A Study on the Physical Properties of Mineral Hydrate Insulation Material Mixed with Basalt Fiber
}

\author{
Jae-Wan Park ${ }^{\dagger}$, Yong-Sik Chu, Sung-Kwan Seo, and Jae-Hyen Jeong \\ Energy \& Environment Division, Korea Institute of Ceramic Engineering and Technology, Jinju 52851, Korea \\ (Received September 1, 2015; Revised November 28, 2015; Accepted December 7, 2015)
}

\begin{abstract}
Mineral hydrate is a new insulation material that compensates for the defects of existing materials. Mineral hydrate is made of inorganic ingredients; therefore, it is nonflammable. The porous structure of mineral hydrate makes the material lightweight and insulating. Mineral hydrate insulation and similar products have been studied and manufactured in Korea and abroad. However, these insulation materials need to improve in terms of strength. In this study, basalt fiber was used to enhance the strength. In order to observe the property changes, compressive strength, heat conductivity, and specific gravity were measured and XRD pattern analysis was performed. These tests confirmed that basalt fiber was effective at improving the strength and lowering the heat conductivity of mineral hydrate insulation.
\end{abstract}

Key words : Mineral hydrate insulation material, Basalt Fiber, Compressive strength, Slurry, Heat insulation

\section{Introduction}

B uilding insulation material is the major construction material for controlling release of thermal energy inside buildings. As the insulation materials are dealt with as an issue for prevention of environmental problems such as preventing destruction of ozone layers through reduction of national energy usage and of greenhouse gases, ${ }^{1)}$ their importance is being increased further. Accordingly, studies have been conducted continuously in relation to insulation materials, and a multitude of products supplementing shortcomings of the existing insulation materials are in development. The insulation materials may be classified largely into inorganic and organic insulation materials. The existing organic insulation materials include styrofoam and polyurethane foam, which have excellent thermal insulation and low costs so as to be applied to many buildings. However, fire is diffused at a very high rate upon its occurrence, simultaneously producing carbon monoxide. Consequently, there are shortcomings of afflicting great damages to buildings as well as being harmful to human bodies. On the other hand, inorganic insulation materials such as rock wool, glass wool, etc. are nonflammable due to the use of inorganic raw materials, accompanying excellent strength and earthquake proof performance, etc. However, their workability is relatively poor, having a disadvantage of increased construction costs. In addition, their use is limited due to vulnerability to

${ }^{\dagger}$ Corresponding author : Jae-Wan Park

E-mail : greatmanj@hanmail.net

Tel : +82-55-792-2464 Fax : +82-55-792-2458 water. ${ }^{2,3)}$ Therefore, new insulation materials capable of overcoming the above shortcomings of organic and inorganic insulation materials should be studied.

ALC (Autoclaved Lightweight Concrete) is a representative lightweight concrete used for outer and inner walls of buildings. To have a lightweight, Property ALC contains about $50 \sim 70 \%$ of pores, and metal aluminum is employed for its manufacturing. Major raw materials for ALC are inorganic materials such as quicklime, cement, etc. which allows securing of nonflammability. Some of these products may exhibit water resistance by using a repellent and simultaneously allow securing of insulation performance. Thus, when inorganic raw materials similar to those of ALC are used and the amount of pores is drastically increased, they may be sufficient for use as an insulation material. Hydrothermal insulation materials (mineral hydrate insulation material) similar to ALC are being produced and used already in Europe, etc. ${ }^{4,5}$ However, the above-mentioned insulation materials have a disadvantage of having reduced strengths due to a large amount of pores. ${ }^{6,7)}$ Therefore, diversified measures to resolve these issues are being sought, one of the method involves incorporation of inorganic fibers. Particularly, inorganic fibers can withstand high-temperature hydrothermal synthesis conditions, and are also known to have excellent characteristics of elastic modulus and tensile strength. ${ }^{8}$

Thus, in the present study, property improvement status was analyzed and evaluated by using a of basalt fiber to solve the problem of strength reduction. 


\section{Experimental procedure}

\subsection{Experimental raw material}

As mentioned above, basalt fiber was applied in the present study to improve the strength of mineral hydrate insulation materials. The basalt fiber has more excellent properties and costs less than the existing glass/carbon fibers, and hence is used in many areas exploiting highstrength characteristics such as automotive parts, lightweight construction materials, nonflammable interior materials and fire curtains, etc.

Figure 1 shows a microstructure of the basalt fiber applied in the present study. The basalt fiber used in the present study had a diameter of about $3 \sim 10 \mu \mathrm{m}$ and a length of about $6 \mathrm{~mm}$. Table. 1 gives the comparative analysis results for basalt fiber and glass fiber. ${ }^{8)}$ Since the basalt fiber has more excellent tensile strength and elastic modulus than the glass fiber, it was considered suitable for reinforcement of the mineral hydrate insulation materials. As the starting materials other than the fiber, cement of $8,000 \mathrm{~cm}^{2} / \mathrm{g}$ in fineness, powders such as silica, anhydrous gypsum, quicklime, mixing water $\left(20^{\circ} \mathrm{C}\right)$, aluminum foaming agent and foam stabilizer were used.

\subsection{Specimen production and property measurement}

To provide a mineral hydrate insulation material, the insulation material was prepared under the combination conditions given in Table 2 . For variations in the combination ratio of basalt fiber, the incorporated amounts of fiber were increased from $0.1 \%$ to $1.0 \%$ at an interval of $0.1 \%$ (named as Ref. and No. 1 10). To produce specimens

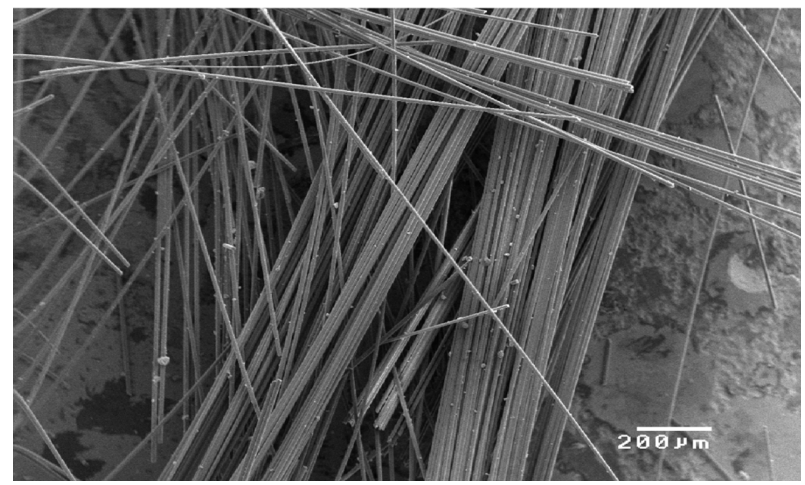

Fig. 1. SEM micrograph of basalt fiber.

Table 1. Properties of Fibers ${ }^{8)}$

\begin{tabular}{cccc}
\hline Properties & Unit & Basalt & Glass \\
\hline Apply Temperature & ${ }^{\circ} \mathrm{C}$ & $-260 \sim 900$ & $-60 \sim 400$ \\
Melting Point & ${ }^{\circ} \mathrm{C}$ & 1,450 & 1,050 \\
Heat Conductivity & $\mathrm{W} /$ & $0.031 \sim 0.038$ & $0.034 \sim 0.04$ \\
Tensile Strength & $\mathrm{MPa}$ & $2,500 \sim 4,800$ & $2,400 \sim 3,400$ \\
Elongation percentage & $\%$ & 3.1 & 4.7 \\
Elastic modulus & $\mathrm{GPa}$ & 89 & 77 \\
\hline
\end{tabular}

according to the above combination conditions, temperature and humidity of the laboratory were controlled to be $25 \pm 2^{\circ} \mathrm{C}$ and $60 \pm 10 \%$, respectively. The starting materials of silica, cement, anhydrous gypsum, quicklime were first mixed in powder condition, secondly followed by second agitation with mixing water and the fiber mixed. After complete mixing of the fiber in the mixing water, the third agitation was performed with addition of a foam stabilizer. Subsequently, the slurry mixture was subjected to the fourth agitation with incorporation of aluminum foaming agent in the slurry. After mixing the slurry was loaded in The mold $20 \mathrm{~cm} \times 20 \mathrm{~cm} \times 20 \mathrm{~cm}$ for foaming. All specimens of Ref. No. 10 were cured and hardened for $24 \mathrm{~h}$ after foaming. Following demolding from the mold after elapse of $24 \mathrm{~h}$, the material underwent hydrothermal synthesis at $180^{\circ} \mathrm{C}$ for $6 \mathrm{~h}$. The insulation material completing by the above process was subjected to constant-weight drying at $100^{\circ} \mathrm{C}$, Then, analysis of XRD, specific weight, compressive strength and thermal conductivity, etc was performed.

To analyze hydrated crystal phases, an X-ray diffraction analyzer (Rigaku Co., D/MAX-2500v, Germany) was used. Xray measurement conditions were $400 \mathrm{kV}, 20 \mathrm{~mA}$, and scan speed of $5 \% \mathrm{~min}$, with 2 obeing fixed in the range of $5 \sim 70^{\circ}$. To check for specific weight changes in the specimens of No. 1 10 including Ref., specific weight was measured according to the standard, "Lightweight foamed concrete block"specification (KS F 2701). Also, to check for strength changes resulting from incorporation of basalt fiber in the mineral hydrate insulation materials. specimens were cut into a size of $10 \mathrm{~cm} \times 10 \mathrm{~cm} \times 10 \mathrm{~cm}$. The cut specimens were then measured by using an universal material tester (Woojin Co., WJ -100S, Korea) following the standard "Lightweight foamed concrete block" (KS F 2701). To observe thermal conduction characteristics of the mineral hydrate insulation materials incorporating basalt fiber, the specimens were cut into a size of $18 \mathrm{~cm} \times 18 \mathrm{~cm} \times$ $3 \mathrm{~cm}$. Subsequently, insulation performance was measured and analyzed by using a thermal conductivity measuring instrument (EKO Co., HC-074, Japan) with the standard "Measurement method for thermal conductivity of thermal insulators" (KS L 9016).

Table 2. Specification of Starting Materials

\begin{tabular}{ccc}
\hline Materials & Specification & Mixing Ratio (\%) \\
\hline OPC & $8,000 \mathrm{~cm}^{2} / \mathrm{g}$ & 50 \\
Quartzite & $8,000 \mathrm{~cm}^{2} / \mathrm{g}$ & 35 \\
Anhydrous Gypsum & $3,000 \mathrm{~cm}^{2} / \mathrm{g}$ & 5 \\
Lime & $4,000 \mathrm{~cm}^{2} / \mathrm{g}$ & 10 \\
Water & $20 \pm 2^{\circ} \mathrm{C}$ & 130 \\
Aluminum & $\mathrm{Y} 250 \mathrm{~N}$ & 0.6 \\
Pore Stabilizer & $\mathrm{PDMS}$ & 0.06 \\
\hline
\end{tabular}

*Y250N : Product name, PDMS : Poly Dimethyl siloxane 


\section{Results and Discussion}

Mineral hydrate insulation materials are composed mainly of tobermorite crystals, which is the major hydrate produced from a hydrothermal synthesis process. Thus, production status of tobermorite crystals was analyzed and reviewed.

XRD was measured for the Ref. without incorporation of basalt fiber, No. 5 incorporating $0.5 \%$ of basalt fiber and No. 10 incorporating $1.0 \%$, and the result are shown in Fig. 2. As shown in Fig. 2, tobermorite crystals were observed in not only the Ref. but also the specimens incorporating basalt fiber (tobermorite 1 st peak present at about $28^{\circ}$, unreacted $\mathrm{SiO}_{2}$ at about $26^{\circ}$ ). However, the tobermorite peak intensity exhibited a tendency toward gradual

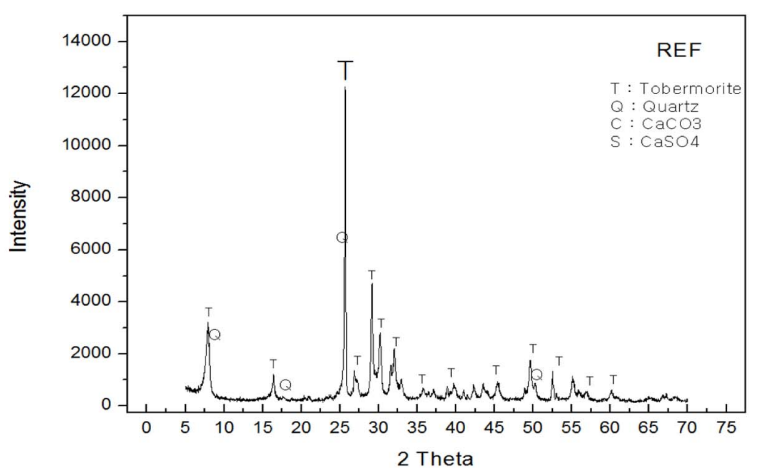

(a)

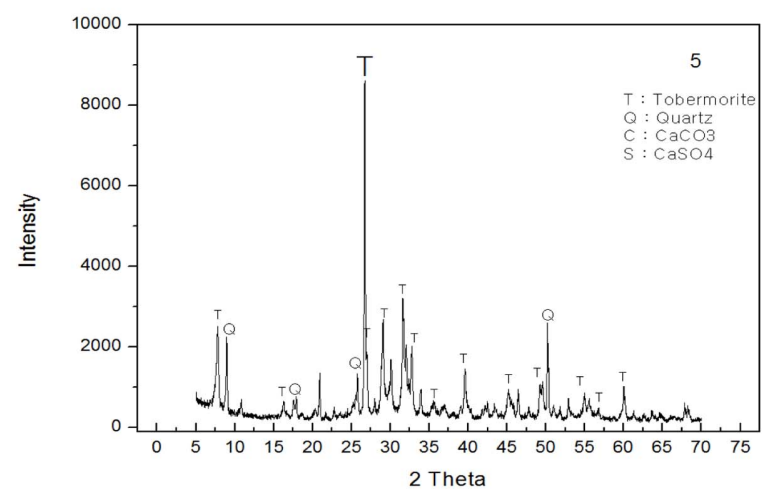

(b)

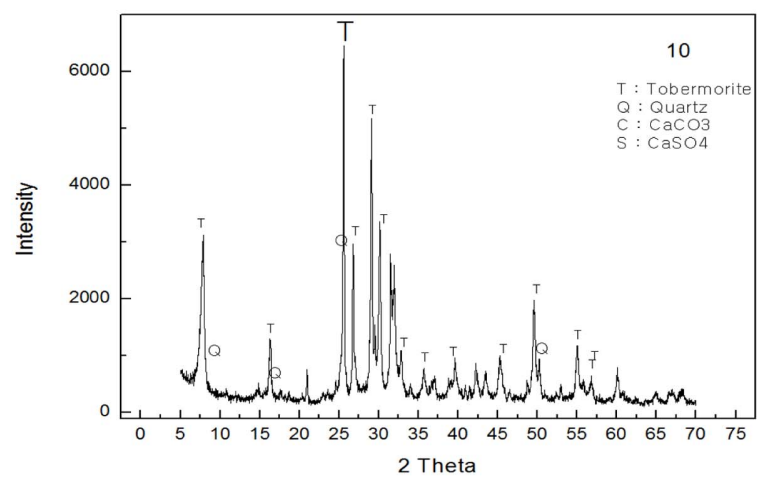

(c)

Fig. 2. XRD patterns of mineral hydrates : (a) reference, (b) No. 5, and (c) No. 10 decrease with an increase in incorporated amounts of the basalt fiber. Namely, while tobermorite peak intensity for the Ref. exceeded about 12,000 CPS (Count Per Sec), it was 8,700 CPS for No. 5, and about 6,500 CPS for No. 10. On the contrary, the 1st peak intensity for unreacted silica exhibited a tendency to increase with an increase in incorporation ratios for basalt fiber. Namely, the hydrothermal reactivity was presumed to be gradually reduced with an increase in the incorporation ratios for the basalt fiber. Pore characteristics and hydrothermal reactivity caused by fiber incorporation will be studied later.

Specific gravity and compressive strength were measured for the Ref. and No. $1 \sim 10$. The result of specific gravity did not show a large difference, and was measured to be about $0.11 \mathrm{~g} / \mathrm{cm}^{3}$. Namely, even if the incorporation ratios for basalt fiber were varied from $0 \%$ to $1 \%$, the ratios could be affirmed not to have a large effect on the specific gravity of the mineral hydrate insulation materials. However, the compressive strength values were changed as a result of incorporation of basalt fiber, which is shown in Fig. 3. As shown in Fig. 3, the compressive strength values were $0.19 \mathrm{MPa}$ for the Ref., $0.23 \mathrm{MPa}$ for No. $1,0.25 \mathrm{MPa}$ for No. 2, $0.24 \mathrm{MPa}$ for No. 3, and $0.26 \mathrm{MPa}$ for No. 5 is the compressive strength values showed a tendency of increase from the minimum of $21 \%$ to the maximum of $37 \%$ as a result of incorporation of basalt fiber. However, when the basalt fiber was incorporated by more than $0.5 \%$, the compressive strength values showed rather a decreasing tendency.

The phenomenon of reduction in compressive strength as shown in Fig. 3 was considered to be due to fiber agglomeration phenomenon resulting from excessive incorporation of the basalt fiber. When an excessive amount of basalt fiber was incorporated, i.e., as the incorporated amount was increased by more than a given ratio, the agglomeration phenomenon was observed more easily. Such phenomenon fiber agglomeration phenomenon is schematically illustrated in Fig. 4. As shown in Fig. 4, the fiber agglomeration phenomenon produced inhomogeneous structures inside the insulation material, and the inhomogeneous structures were presumed to be increased further with an increase in the incorporation ratios.

Eventually, the inhomogeneous structures produced by

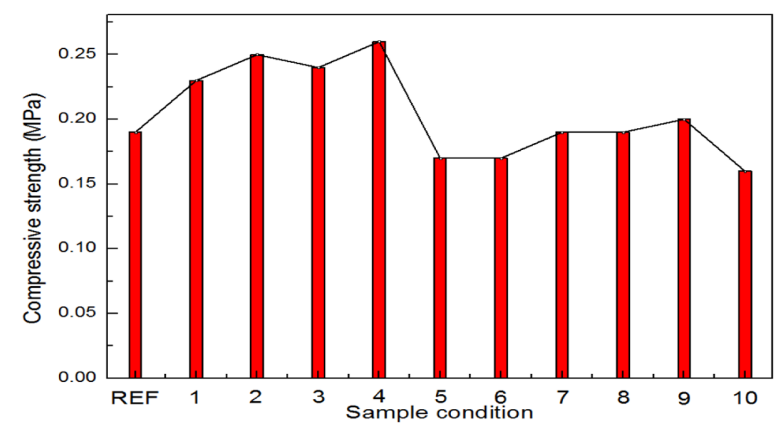

Fig. 3. Compressive strength of mineral hydrates. 


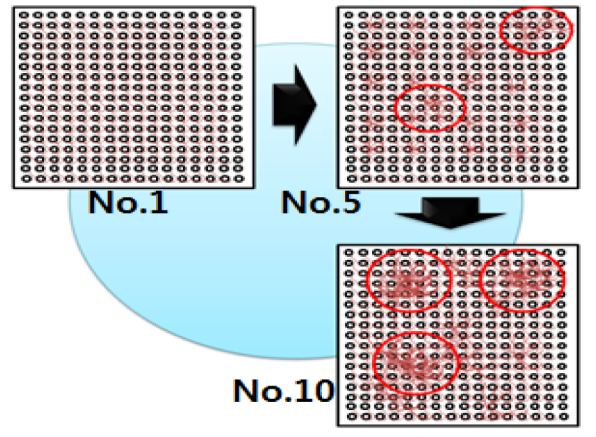

Fig. 4. Schematic diagram of fiber aggregation.

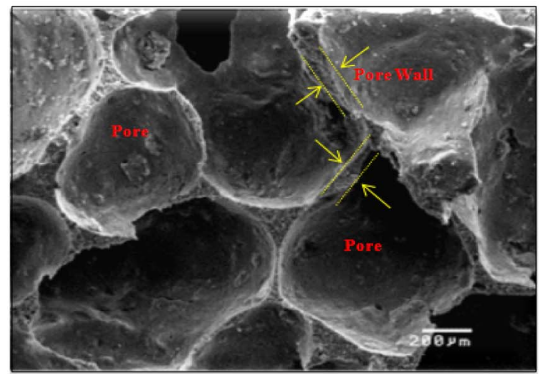

(a) Ref.

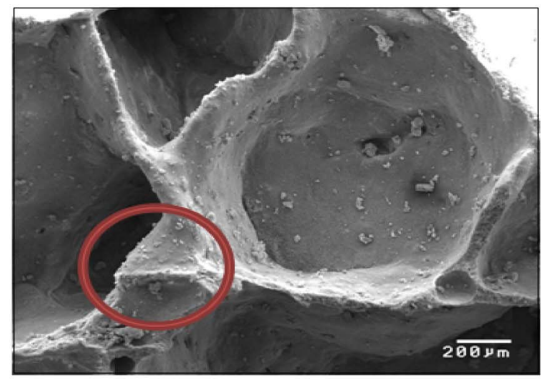

(b) No. 5

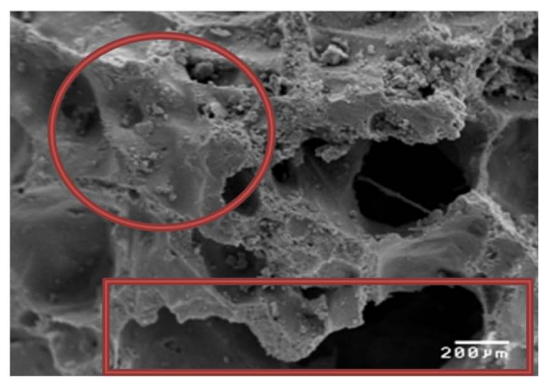

(c) No. 10

Fig. 5. SEM micrograph of mineral hydrates.

fiber agglomeration phenomenon was considered to have acted as a defect inside of the insulation material to contribute to the reduction in compressive strengths for the insulation material.

For more detailed observation of the effects on basalt fiber, microstructures of the insulation material were examined. As shown in Fig. 6, pores of the Ref. could be affirmed to consist mainly of closed pores, with the pore walls being

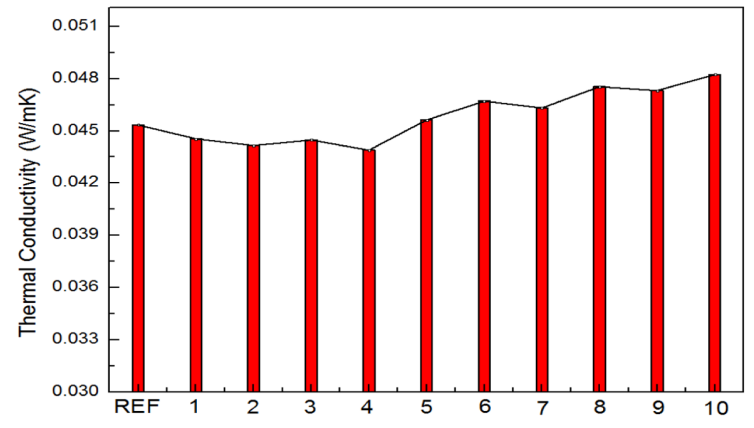

Fig. 6. Thermal conductivity of mineral hydrates.

constant. In addition, No. 4 also had constant pore walls along with closed pores, and the fibers were particularly affirmed to be positioned in the pore wall part. Namely, when a small amount of fiber was incorporated, the fibers could be seen to be mainly attached to the pore walls. On the other hand, the phenomenon different from the above was also observed when an excessive amount fiber was incorporated.

In No. 10 with $1.0 \%$ of basalt fiber incorporated, the incorporated fibers penetrated not only the pore walls but also the pores, and the agglomeration phenomenon also occurred in multitudes. Particularly, thick and not constant defective pore walls were produced as a result of large amount of fibers impeding slurry expansion in the initial slurry mixing process. It could also be affirmed that the defective pore walls produced in the above process caused conversion of the inside pores to connected pores rather than closed pores.

Measurement results for thermal conductivity as the major characteristics of insulation materials are shown in Fig. 6. All specimens had a thermal conductivity in the range of $0.043 \sim 0.048 \mathrm{~W} / \mathrm{mK}$. And it was found that the value change of thermal conductivity had a similar tendency with that of compressive strength.

Namely, although thermal conductivities were reduced up to No. 4 in comparison with the Ref., the increasing results for No. 5 and up were derived. As mentioned above, this is related to homogeneity in the insulation materials. When the basalt fibers were homogeneously positioned, changes in pore walls and pores were not observed. However, when a large amount of fiber produced an inhomogeneous structure as shown in Fig. 5 the inside pores were converted from closed pores to connected pores. Namely, the interconnected pores were considered to have resulted in degraded insulation characteristics as heat transfer due to radiation and convection became easier.

Also, large pore forms inside the rectangle for No. 10 in Fig. 5 were observed inside the specimens of the same specific gravity simultaneously with the agglomeration phenomenon inside the circle, where the large pores inside the rectangle were also increased as the agglomeration phenomenon was increased. Such factor was also considered to be responsible for the tendency toward property defects. 


\section{Conclusions}

The present study was performed to confirm property improvement for mineral hydrate insulation materials as a result of incorporation of basalt fiber. In addition, optimum combination ratios for the basalt fiber were also reviewed through the property analysis for mineral hydrate insulation materials, and the following conclusions have been derived from the above study.

1. For an increase in compressive strength and thermal insulation for mineral hydrate insulation performance materials, it could be affirmed that the incorporation ratio for basalt fiber should be controlled to be $0.4 \%$.

2. As the incorporation ratios for basalt fiber were increased, fiber agglomeration phenomenon occurred in multitudes, and such fiber agglomeration phenomenon was affirmed to cause conversion of independent pores to interconnected pores.

3. Incorporation of basalt fiber had a close correlation with pore changes in mineral hydrates, and such pore changes also had an effect on property changes in mineral hydrate insulation materials.

4. Since the inherent thermal insulation performance of basalt fiber was more excellent than the thermal insulation performance of mineral hydrate insulation materials, it was affirmed that the fibers were adsorbed onto pore walls for the simultaneous effects on reinforcement of strength and lowering of thermal conductivity.

\section{REFERENCES}

1. J. W. Park, "Physical Properties of Mineral Hydrate Insulation used Desulfurization Gypsum," J. Rec. Const. Resources, 2 [4] 291-96 (2014).

2. X. Chen, S. Wu, and J. Zhou, "Influence of Porosity on Compressive and Tensile Strength of Cement Mortar," Constr. Build. Mater., 40 869-74 (2013).

3. O. Ünal, T. Uygunoğlu, and A. Yildiz, "Investigation of Properties of Low-Strength Lightweight Concrete for Thermal Insulation," Build. Environ., 42 [2] 584-90 (2007).

4. S.-K. Seo, "A Study on Fabrication and Characterization of Inorganic Insulation Material by Hydrothermal Synthesis Method," J. Rec. Const. Resources, 1 [3] 219-24 (2013).

5. M. Jerman and R. Černý, "Effect of Moisture Content on Heat and Moisture Transport and Storage Properties of Thermal Insulation Materials," Ener. Build., 53 39-46 (2012).

6. Z. Pan, H. Li, and W. Liu, "Preparation and Characterization of Super Low Density Foamed Concrete from Portland Cement and Admixtures," Constr. Build. Mater., 72 [15] 256-61 (2014).

7. M. Jerman, M. Keppert, J. Výborný, and R. Černý, "Hygric, Thermal and Durability Properties of Autoclaved Aerated Concrete," Constr. Build. Mater., 41 352-59 (2013).

8 J. W. Lee and Y. H. Kim, "Fabrication of Carbon/Basalt Hybrid Composites and Evaluation of Mechanical Properties," Compos. Res., 27 [1] 14-8 (2014). 